\section{AFRICAN NECTAR DRINKERS}

The Sunbirds of Southern Africa; also the Sugarbirds, the White-Eyes and the Spotted Creeper

By C. J. Skead, assisted by Cecil M. Niven, J. M. Winterbottom and Richard Liversidge. Pp. $351+22$ plates + gramophone record. (Cape Town and Amsterdam: A. A. Balkema, 1967. Published for the Trustees of the South African Bird Book Fund.) Rs. 8.50.

THIs is the second of a series of monographs dealing with certain groups of birds as represented in Southern Africa. It emanates largely from the Percy Fitzpatrick Institute of African Ornithology attached to the University of Cape Town, and its publication is sponsored by the South African Bird Book Fund. It gives a systematic account of the species of four passerine families of the Old World tropics and subtropics, three of them having in common the habit of drinking flower-nectar; two are represented in the area by single genera, puzzling in their taxonomic relationships.

The sunbirds (Nectariniidae) are represented by twenty species and their treatment thus occupies the larger part of the volume. Sunbirds correspond ecologically to the hummingbirds of the New World; and they likewise show brilliantly coloured plumages, well illustrated here by John Perry. Of the white-eyes (Zosteropidae) there are just three representatives, the main concentration lying further to the east. The genus Promerops is peculiar to the area and has two species; it is commonly placed among the honeyeaters (Meliphagidae), otherwise an Australasian family, but in this work judgment is reserved by keeping it in a family of its own. The rather inapt name "sugarbird" probably relates to the remarkably close association between the birds and the Protea bush, suikerbos in Afrikaans. The spotted creeper, of the small genus Salpornis, shows resemblance to the treecreepers (Certhiidae) but is usually regarded as an aberrant nuthatch (Sittidae); it has a slender decurved bill, like the sunbirds and sugarbirds, but is not a nectar drinker.

There is a general review of each family, after which the species are treated separately under such headings as local names, distribution in South Africa and elsewhere, field characters, habits, habitat, food, voice, breeding and taxonomy. In addition to the ten colour plates and twelve plates of photographs, there are line drawings illustrating breeding techniques, courtship attitudes and the like; and there are maps showing distribution in Southern Africa. In a pocket at the back there is a small two-sided gramophone record of sunbird calls and songs, edited by June Stannard. The book is well arranged and attractively produced. In all, a great deal of both old and new information has been usefully put together in convenient form.

LANDSBOROUGH THOMSON

\section{CATALOGUE OF NYCTERIBIIDS}

\section{An Illustrated Catalogue of the Rothschild Collection of Nycteribiidae (Diptera) in the British Museum (Natural History)}

By Oskar Theodor. Pp. viii $+506+5$ plates. (Publication No. 655.) (London: British Museum (Natural History), 1967.) $360 s$.

THE dearth of comprehensive articles on the systematics of Nycteribiids is rectified by this outstandirg and essentially monographic opus, which presents a revision of the family as a whole. The number of taxa described as new to science is: one subfamily (of a total of two), one genus (of eight), one subgenus (of nine), thirty-seven species (of 189) and two subspecies (twelve non-nominate).

After discussing and illustrating the complex morphological characters used in the taxonomy of Nycteribiids, the technical terms are defined in a special glossary which cites figure references for further clarification. The systematics of the various taxa are then presented and the differential characters summarized in table form. The names and authors of all species treated are listed. Dichotomous keys to these genera, subgenera, species and subspecies usually employ multiple and alternative diaguostic characters, cite page and figure references, and at times include geographic notes. The taxonomic section resembles in format the laudable system of the companion volumes on $\mathrm{S}$ phonaptera by Hopkins and Rothschild. Thus, complete taxonomic citations are given for each taxon, including designation of synonyms, and succinct diag 1 oses and descriptions are presented, together with notes on hosts and distribution (supplemented by six maps). The cardinal taxonomic features are illustrated in a set of 898 figures of drawings and nine photomicrographs. Synonyms, misidentifications and major references to valid names can be recognized at a glance in the index.

The figures are clear and illustrate well the characters used in taxonomy. The keys are simple, terse, accurate and sound, and their use is facilitated by the wealth of excellent illustrations. The diagnoses and descriptions are lucid and deal with essential characters, emphasizing why the scheme of systematics employed can confidently be regurded as authoritative throughout.

Despite the complexity of the subject and the innumerable details presented, the book is remarkably free from errors, and in general the volume indicates superior editing and workmanship by the author, by the Hon. Miriam Rothschild and by the staff of the British Museum.

Dr Theodor is to be commended on having prepared a definitive opus which, for the first time, enables the nonspocialist to identify Nycteribiids on a global basis and thereby lays the ground work for much needed research on the habits and bionomics of Nycteribiids and on their possible role as vectors of infection. The volume also contributes to our knowledge of evolution and zoogeography and of the affinities of these parasites and their hosts.

ROBER'T TraUb

\section{PLANT TERPENES}

\section{Terpenoids in Plants}

Edited by J. B. Pridham. (Proceedings of the Phytochomical Group Symposium, Aberystwyth, April 1966.) Pp. $x i+257$. (London: Academic Press, Inc. (London), Ltd.; New York: Academic Press, Inc., 1967.) 70s.: $\$ 12.50$.

The essential oils of plants were among the first naturally occurring materials with which organic chemists concerned themselvos. Interest in plant terpenic components and in more complex terpenes from other sources continues unabated and has, indeed, been quickened by the introduction of modern techniques.

The present volume is based on the proceedings of a symposium held under the auspices of the Phytochemical Group in the spring of 1966 . The contributions cover a wide field, but it is perhaps a sign of the times that of the twelve chapters seven are concerned in whole or in part with biosynthesis. These include a useful review of methods for the proparation of tritiated and deuterated mevalonate and their application in unravelling the stereochemical course of the biosynthesis of squalene. There aro also accounts of the biosynthesis and metabolism of monoterpenes, the in vivo and in vitro skeletal transformations of diterpenes, the biosynthesis of car. denolides, bufadienolides and steroid sapogenins, phytosterol biosynthesis, the biosynthesis of terpenoid quinones and a fascinating review of the variety of sesquiterpenes, mostly derivatives of furan, found in the essential oil of Myoporum deserti A. Cunn. Other chapters are concerned with a discussion of the biological significance of terpenes 